\title{
S100P contributes to chemosensitivity of human ovarian cancer cell line OVCAR3
}

\author{
ZHIJUAN HE ${ }^{1}$, JIANHUA GAO ${ }^{1}$, QI WANG ${ }^{1}$, MIN LIU ${ }^{2}$, YIXUAN LI ${ }^{2}$, \\ XIN LI $^{2}$, HUA TANG ${ }^{2}$ and JIANHUA ZHENG ${ }^{1}$ \\ ${ }^{1}$ Department of Obstetrics and Gynecology, the First Affiliated Hospital of Harbin Medical University, Harbin, HLJ 150010; \\ ${ }^{2}$ Tianjin Life Science Research Center, Tianjin Medical University, Tianjin 300070, P.R. China
}

Received February 2, 2008; Accepted March 26, 2008

DOI: $10.3892 /$ or_00000010

\begin{abstract}
S100P is a member of the S100 family of calciumbinding proteins. Our previous studies have demonstrated its significant downregulation in oxaliplatin-resistant colon cancer cell line. The present study investigated whether it plays a role in the regulation of chemosensitivity to anticancer drugs using human ovarian cancer cell line OVCAR3. We firstly overexpressed S100P in the OVCAR3 cell line, and evaluated the expression level of S100P by semiquantitative RT-PCR, Western blotting and immunofluorescence assay. 3-(4,5-Dimethylthiazol-2-yl)-2,5diphenyltetrazolium (MTT) assay indicated that overexpression of S100P sensitized OVCAR3 cells for chemotherapeutic drugs (paclitaxel, oxaliplatin, 5-fluorouracil, etoposide and epirubicin) induced cytotoxicity more than vector-only controls. Further studies showed that downregulation of S100P by RNA interference in OVCAR3 cells led to a significant increase of resistance to each of these anticancer drugs. Taken together, our results suggest that $\mathrm{S} 100 \mathrm{P}$ plays an important role in regulation of chemosensitivity to anticancer drugs in ovarian cancer cells. Using S100P as a molecular biomarker may increase our ability to predict tumor drug response in ovarian cancer.
\end{abstract}

\section{Introduction}

Cancer cell resistance is considered to be one of the major reasons for the failure of chemotherapy in most cancer patients. Some tumors are intrinsically resistant to treatment, whereas others acquire resistance with exposure to structurally unrelated drugs. A frustrating property of such acquired resistance is

Correspondence to: Dr Jianhua Zheng, 23 Youzheng Street, Nangang Block, Harbin, HLJ 150010, P.R. China

E-mail: doctorzheng52@yahoo.com.cn

Dr Hua Tang, 22 Qixiangtai Street, Heping Block, Tianjin 300070, P.R. China

E-mail: htang2002@yahoo.com

Key words: S100P, drug resistance, ovarian cancer that the tumors not only become resistant to the drugs originally used to treat them, but may also become crossresistant to other drugs with different mechanisms of action. Drug resistance, whether intrinsic or acquired, is believed to cause treatment failure in over $90 \%$ of patients with metastatic cancer. Clearly, if drug resistance could be overcome, the impact on survival would be highly significant. Improvements in patient response are going to depend on elucidating the molecular mechanisms of cellular resistance to chemotherapy. Resistance to treatment with anticancer drugs results from a variety of factors including individual variations in patients and somatic cell genetic differences in tumors, even those from the same tissue of origin. In previous studies, we compared gene expression profile of oxaliplatin-resistant colonic cancer cell line with oxaliplatin-sensitive parental cell line using an in-house oligomicroarray, while a number of genes were differentially expressed (1). Significant downregulation of $\mathrm{S} 100$ calcium-binding protein $\mathrm{P}$ (S100P) was confirmed in the oxaliplatin-resistant colon cancer cell line, which suggested that S100P was associated with chemosensitivity in this drugresistant cell line.

$\mathrm{S} 100 \mathrm{P}$ is a member of the $\mathrm{S} 100$ calcium-binding protein family. The $\mathrm{S} 100$ family of proteins consists of $\mathrm{Ca}^{2+}$ - binding proteins of the EF-hand type with at least 25 members. S100 proteins can function as both intracellular and extracellular signaling molecules. One of the least studied members of the $\mathrm{S} 100$ family is $\mathrm{S} 100 \mathrm{P}$, a 95 -amino acid protein first purified from placenta with a restricted cellular distribution $(2,3)$. Expression of S100P has been noted in esophageal epithelial cells during their differentiation, indicating that it may play a role in normal development (4). S100P is expressed in several types of cancer including breast (5), colon (6), prostate (7), lung (8), and pancreatic cancer (9), and gained recognition for its role in cancer. S100P is also expressed in some noncancerous diseases, including inflammatory bowel disease, alopecia areata and psoriasis (10).

Ovarian cancer is a malignant gynaecology cancer causing high mortality for drug resistance. In this study, we used OVCAR3, an ovarian cancer cell line with endogenous expression of S100P, to investigate whether the expression level of S100P could influence the chemosensitivity of cancer cells. S100P was overexpressed in OVCAR3 cells and the effect on chemosensitivity was assessed. In a complementary experiment, we downregulated S100P expression by small 
interfering RNA (siRNA) in OVCAR3 and evaluated the effect of decreased S100P expression on chemosensitivity. We selected the commonly used anticancer agents in the clinic, such as paclitaxel, oxaliplatin, 5-fluorouracil, etoposide and epirubicin. Overexpression of S100P in OVCAR3 cells was found to increase sensitization for all the chemotherapeutic agents. Furthermore, decreasing S100P expression in OVCAR3 cells enhanced their resistance to chemotherapy. Therefore, S100P may be a useful target for the development of new therapies for ovarian cancers.

\section{Materials and methods}

Cell culture. The surface epithelial ovarian cancer cell line, OVCAR3, was maintained in RPMI-1640 medium (Gibco, USA) supplemented with $100 \mathrm{U} / \mathrm{ml}$ penicillin, $100 \mu \mathrm{g} / \mathrm{ml}$ streptomycin, and $10 \%$ fetal bovine serum (FBS) and was maintained at $37^{\circ} \mathrm{C}$ in a humidified atmosphere containing $5 \% \mathrm{CO}_{2}$.

DNA constructs and stable transfection of OVCAR3 cells. The full coding region of human S100P was cloned by PCR with sense, (5'-GTCTGAATTCAGCACCATGACGGAACT AGAG-3') and antisense, (5'-GGCTCGAGTTGAGTCCTGC CTTCTCAAAG-3') (internal EcoRI and XhoI restriction sites and starting ATG codon are underlined and in bold, respectively) primers using Taq DNA polymerase (Fermentas, Lithuania). The PCR product was then digested with EcoRI and $X h o I$ and inserted between the same DNA restriction sites of pcDNA3 vector (Invitrogen, USA). The resulting pcDNA3-S100P plasmid encoded full length of human S100P protein. The sequences of obtained constructs were verified by DNA sequencing. OVCAR3 cells were transfected with pcDNA3-S100P or pcDNA3 as control using Lipofectamine 2000 (Invitrogen). After $24 \mathrm{~h}$, fresh medium was added to the cells containing the selection reagent G418 $(500 \mu \mathrm{g} / \mathrm{ml})$ (Sigma, Germany). Selection was continued for 14 days, with the medium being refreshed every alternate day. Clones were isolated and S100P overexpression was confirmed by semiquantitative RT-PCR (sqRT-PCR), Western blot analysis and immunofluorescence. The cells were tested for drug sensitivity using the MTT analysis as described below.

RNA interference/transfection of synthetic small interfering $R N A$. The siRNA sequence targeting S100P corresponded to the coding region 251-271 (5'-CCTGTCACAAGTACTTTG AGA-3') relative to the start codon. The siRNA duplex with the following sense and antisense sequences was used: 5'-CCUGUCACAAGUACUUUGAGAdTdT-3' (sense) and 5'-UCUCAAAGUACUUGUGACAGGdTdT-5' (antisense). Negative control siRNA duplex has the following sequences: 5'-UUCUCCGAACGUGUCACGUdTdT-3' (sense) and 5'ACGUGACACGUUCGGAGAAdTdT-3' (antisense). All of the siRNA duplexes were synthesized. OVCAR3 cells in exponential phase of growth were transfected with $120 \mathrm{nM}$ of S100P siRNA or negative control siRNA using Oligofectamine Reagent (Invitrogen), according to the manufacturer's protocol. Then the expression level of S100P was examined by sqRTPCR and Western blot analysis. For the MTT assay, cells ( $2 \times 10^{5}$ per well) were cultured in 6 -well plate. After $48 \mathrm{~h}$ of transfection, cells were seeded to 96-well plate and subjected to the MTT analysis as described below.

RNA isolation and semiquantitative RT-PCR analysis of $S 100 P$. Total cellular RNA was extracted and purified using the TRIzol reagent (MRC, USA). The extracted RNA was quantified by absorbance at $260 \mathrm{~nm}$ and its quality was assessed by the ratio of absorbance at 260 and $280 \mathrm{~nm}$ using $\mu$ Quant Universal Microplate spectrophotometer (Bio-Tek Instruments, Winooski, VA, USA). Integrity of the isolated RNA was then checked by determining the ratio of $28 \mathrm{~S}$ and $18 \mathrm{~S}$ after electrophoresis in $1 \%$ agarose gel. First-strand cDNA was transcribed from $1 \mu \mathrm{g}$ of total RNA in a total volume of $20 \mu \mathrm{l}$ using an oligo-dT primer and M-MLV reverse transcriptase (Promega, USA) at $42^{\circ} \mathrm{C}$ for $60 \mathrm{~min}$. After termination of the reaction, $1 \mu 1$ of cDNA was used as the template for PCR amplification of S100P or B-actin as a control in a $50 \mu 1$ reaction volume. The cycling conditions were $94^{\circ} \mathrm{C}$ for $5 \mathrm{~min}$, followed by 30 (for S100P) or 25 (for B-actin) cycles of $94^{\circ} \mathrm{C}$ for $30 \mathrm{sec}, 58^{\circ} \mathrm{C}$ for $60 \mathrm{sec}$ and $72^{\circ} \mathrm{C}$ for $1 \mathrm{~min}$, additional $10 \mathrm{~min}$ extension at $72^{\circ} \mathrm{C}$ after the last cycle. The sequences of the primer pairs were: S100P: sense 5'-GTCTGAATTCAGCACCATGACGGAACTAGAG-3' and antisense 5'-GGCTCGAGTTGAGTCCTGCCTTCT CAAAG-3' and $ß$-actin: sense 5'-CGTGACATTAAGGAG AAGCTG-3' and antisense 5'-CTAGAAGCATTTGCG GTGGAC-3'. Each primer set was amplified using an optimized number of PCR cycles to ensure the linearity requirement for semi-quantitative RT-PCR analysis. PCR products were separated on a $1 \%$ agarose gel and visualized by ethidium bromide staining under ultra-violet light. The expected sizes for the S100P and B-actin PCR products were 308 and $500 \mathrm{bp}$, respectively. For quantitation of cDNA, densitometric analysis of a digital image of the agarose gel was performed using LabWorks software (UVP Inc., Upland, CA, USA). Each PCR product was compared with that obtained by amplifying $B$-actin cDNA in the same sample, and band intensities were determined by densitometry.

Western blot analysis. Cell extracts were prepared by collecting and washing cells in ice-cold PBS and collecting in lysis buffer (25 mM Tris- $\mathrm{HCl} \mathrm{pH} 7.4,1 \%$ Triton $\mathrm{X}-100,150 \mathrm{mM} \mathrm{NaCl}$, $1 \mathrm{mM}$ PMSF). Cell lysates were centrifuged at $12000 \mathrm{x} \mathrm{g}$ for $15 \mathrm{~min}$ to remove nuclei and cell debris, leaving protein concentrations in the supernatant. Equal amounts of cell extracts were diluted with an $5 x$ loading buffer $(250 \mathrm{mM}$ Tris- $\mathrm{HCl} \mathrm{pH}$ 6.8, 20\% glycerol, 4\% SDS, 10\% ß-mercaptoethanol, $0.005 \%$ bromophenol blue), heated to $100^{\circ} \mathrm{C}$ for $5 \mathrm{~min}$, colded in ice for $2 \mathrm{~min}$, and applied to $12 \%$ polyacrylamide gels containing SDS (SDS-PAGE). Separated proteins were transferred to nitrocellulose membrane. Membranes were incubated for $1 \mathrm{~h}$ at room temperature in blocking buffer consisting of $5 \%$ non-fat dry milk, $137 \mathrm{mM} \mathrm{NaCl}$, $20 \mathrm{mM}$ Tris- $\mathrm{HCl}\left(\mathrm{pH} 7.6\right.$ at $\left.21^{\circ} \mathrm{C}\right)$, and $0.1 \%(\mathrm{w} / \mathrm{v})$ Tween-20. After blocking, the membranes were incubated with primary antibodies overnight at $4^{\circ} \mathrm{C}$ rabbit anti-S100P (1:100 dilution) (Saier Co., P.R. China), monoclonal anti- $\gamma$-tubulin $(1: 2,000$ dilution) (Sigma) and then incubated with peroxidaseconjugated secondary IgG antibodies (Sigma, Germany) for $1 \mathrm{~h}$ at room temperature and developed with enhanced 
A
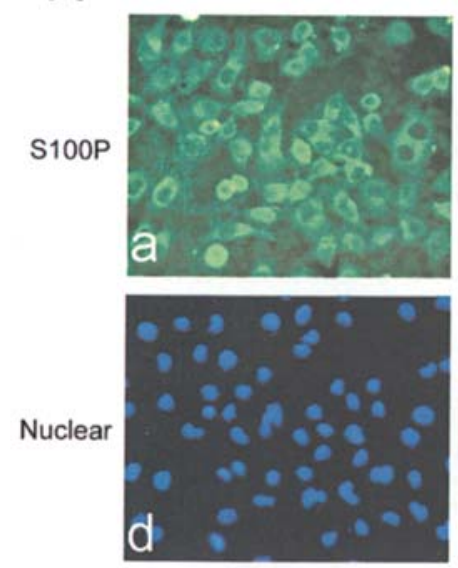

PCDNA3
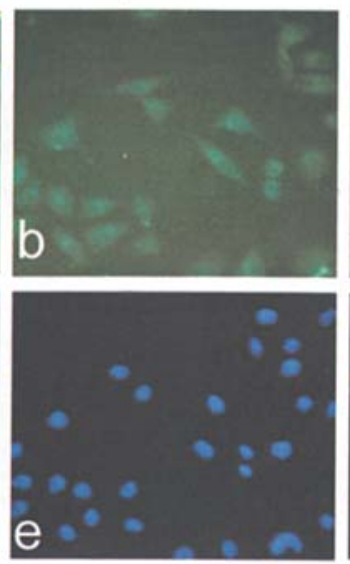

Normal
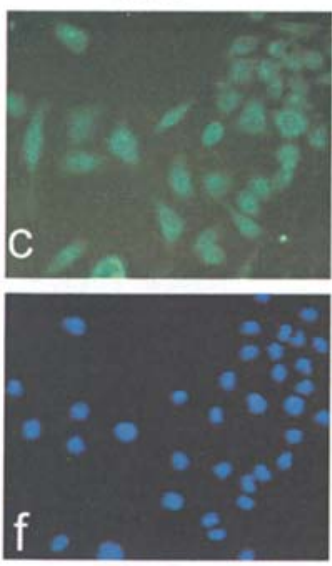
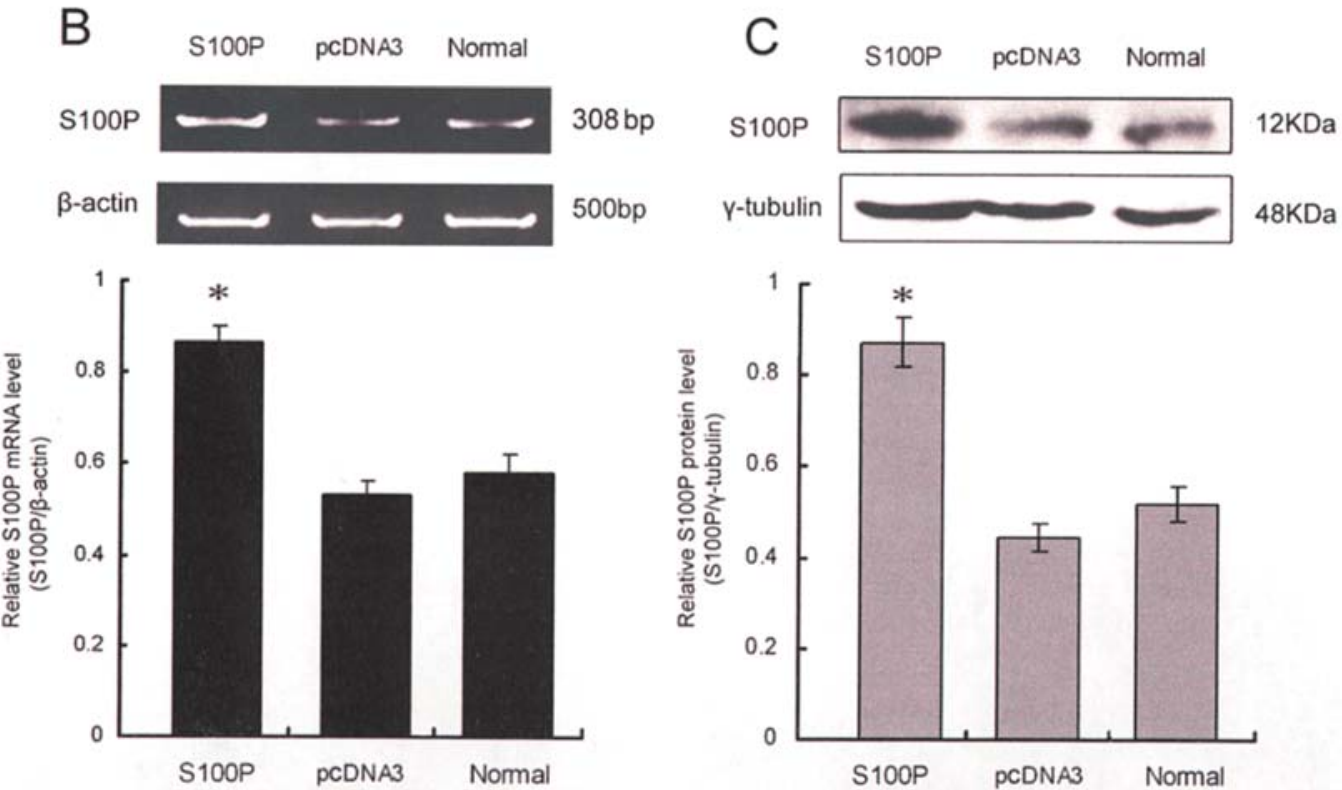

Figure 1. Expression of S100P in OVCAR3 cell line. (A) Immunofluorescence staining for S100P (green) transfected cells. (a) is stable OVCAR3 cell line which was transfected with pcDNA3-S100P, (b) is pcDNA3 vector transfected cells, (c) is normal OVCAR3 cells. Cell nuclei were counterstained with DAPI (blue) (magnification x400). (B) OVCAR3 cells were transfected with plasmids containing S100P or empty vector, and S100P levels were analyzed by semiquantitative RT-PCR. B-actin was used as internal control. The results are the representatives of at least three independent experiments. (C) Western blot analysis showing expression levels of S100P protein within the cell lysates transfected with plasmids containing S100P or empty vector. $\gamma$-tubulin was used as internal control. The results are the representatives of at least three independent experiments. Data values are the mean $\pm \mathrm{SD} ;{ }^{*} \mathrm{p}<0.05$ compared with normal control or empty vector.

chemiluminescence reagent kit (Pierce, USA). Densitometry was run on LabWorks software and values were calculated ratio to $\gamma$-tubulin densitometry values.

MTT-assay for the drug sensitivity. The sensitivity of the cells to paclitaxel, oxaliplatin, 5-fluorouracil, etoposide and epirubicin was detected with MTT assay. Cells $(5,000)$ were cultured in each well in a 96-well plate for $24 \mathrm{~h}$. The culture medium was replaced with the medium containing serial dilutions of various chemotherapeutic drugs. After $48 \mathrm{~h}$ of drug incubation, $10 \mu 1$ 3-(4,5-dimethylthiazol-2-yl)-2,5diphenyltetrazolium (MTT) $(5 \mathrm{mg} / \mathrm{ml})$ (Sigma) was added to each well and incubated for an additional $4 \mathrm{~h}$. The plates were then centrifuged $(500 \mathrm{x} \mathrm{g}, 10 \mathrm{~min})$ and the supernatant was removed. Dimethyl sulfoxide (DMSO) (100 $\mu 1 /$ well) was added to dissolve the blue formazan crystals converted from
MTT by live cells. Cell viability was assessed by absorbance at $570 \mathrm{~nm}$ measured on $\mu$ Quant Universal Microplate spectrophotometer (Bio-Tek Instruments). The absorbance $(A)$ values of formazan produced was calculated as a percentage of the control untreated wells and, transferred to a doseresponse curve. The survival rate of tumor cells to each drug with different concentrations was calculated as follows: survival rate $=100 \% \times\left(\mathrm{A}_{\text {drug treated }}-\mathrm{A}_{\text {blank }}\right) /\left(\mathrm{A}_{\text {control }}-\mathrm{A}_{\text {blank }}\right)$. The $\mathrm{IC}_{50}$ value resulting from $50 \%$ inhibition of cell growth was calculated. Each concentration of drugs was measured in triplicate wells on the same plate in three independent experiments.

Immunofluorescence. OVCAR3 cells were grown to $90 \%$ confluency on glass slides and were washed with PBS, and then fixed in $4 \%$ paraformaldehyde for $30 \mathrm{~min}$ at $4{ }^{\circ} \mathrm{C}$. Fixed 

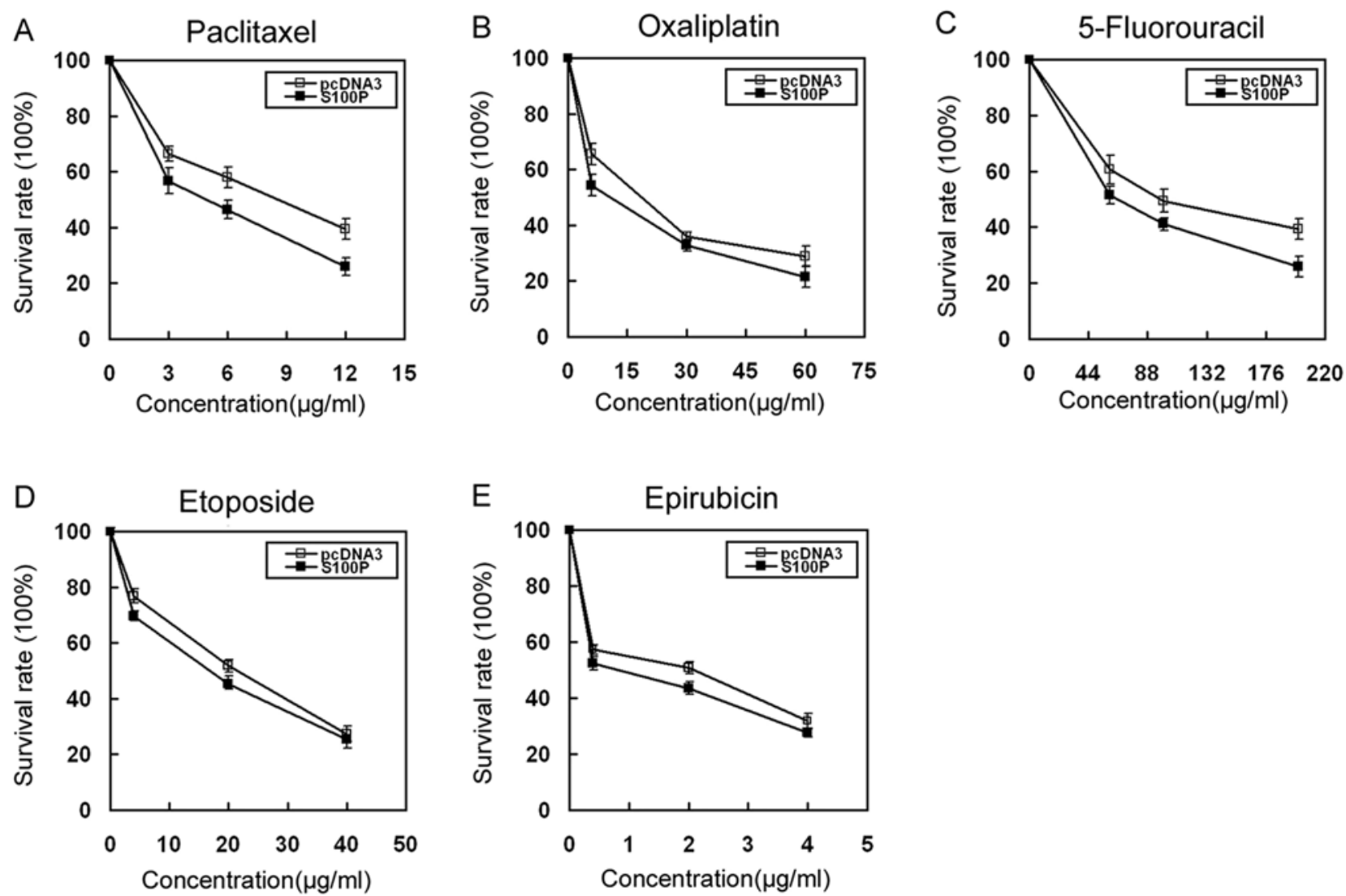

Figure 2. Enhanced sensitivity to chemotherapeutic drugs in S100P overexpressed OVCAR3 cells. Cells were incubated with the indicated concentrations of paclitaxel (A), oxaliplatin (B), 5-fluorouracil (C), etoposide (D) and epirubicin (E) for $48 \mathrm{~h}$, and cell viability was measured by MTT assay. S100P overexpressed OVCAR3 cells have more sensitivity to these drugs than vector-only controls. It means the statistics significance with the code. Data values are the mean $\pm \mathrm{SD}$.

cells were washed with PBS and permeabilized with $0.5 \%$ Triton X-100 for $10 \mathrm{~min}$. Cells were washed three times in PBS and covered with blocking buffer (10\% donkey serum in $\mathrm{PBS}$ ) for $2 \mathrm{~h}$ before staining at $4^{\circ} \mathrm{C}$. The primary $\mathrm{S} 100 \mathrm{P}$ antibody (Saier) diluted 1:50 were applied to sections at $4^{\circ} \mathrm{C}$ overnight in a humidified chamber. S100P were visualised by fluorescein conjugated goat anti-rabbit secondary antibody (Calbiochem, USA) diluted 1:200 at $4^{\circ} \mathrm{C}$ for $1 \mathrm{~h}$. Sections were counterstained with 4',6-diamidino-2-phenylindole (DAPI) diluted 1:1000. After the cells were washed three times with PBS, and finally mounted with aqueous mounting medium. The images were observed on a Nikon Eclipse 600 fluorescence microscope with digital camera Nikon DXM 1200 .

Statistical analysis. Statistical analysis was performed using SPSS software. Studies were performed in triplicate with the results expressed as means \pm SD as appropriate. Results were considered statistically significant at $\mathrm{p}<0.05$ obtained with a two-tailed Student's t-test.

\section{Results}

Production of S100P overexpressing OVCAR3 cells. The human ovarian cancer cell line OVCAR3 was validated to have endogenous expression of the S100P by Western blot analysis and immunofluorescence (Fig. 1). In order to simulate their induced overexpression and to infer their effect on chemotherapeutic drugs resistance, OVCAR3 cells were transfected S100P expression vector (pcDNA3-S100P), and isolated stable clones expressing S100P by neomycin (G418). The expression of S100P mRNA and protein in stably transfected OVCAR3 cells were confirmed by sqRT-PCR, Western blot analysis and immunofluorescence. Compared to parental and vector controls, a higher expression of $\mathrm{S} 100 \mathrm{P}$ protein and increased levels of S100P mRNA was detected in the pcDNA3-S100P transfected OVCAR3 cells. The expression level of S100P in cells transfected with pcDNA3 vector was similar to that of normal cells.

Effect of S100P overexpression on chemosensitivity in OVCAR3 cells. Our previous studies have showed that the expression levels of S100P in oxaliplatin-resistant colonic cancer cells were lower than that of compared parent cells, suggesting that $\mathrm{S} 100 \mathrm{P}$ gene may participate in the resistance to chemotherapeutic drugs in tumor cells. To test this possibility, we investigated the role of S100P on drug-resistance by examined its effect on sensitivity to several common anticancer agents in OVCAR3 cells. Sensitivities of OVCAR3 cells to various concentrations of paclitaxel, oxaliplatin, 5-fluorouracil, etoposide and epirubicin were determined, respectively, by an MTT assay. Survival rates were plotted on curves (Fig. 2). The $\mathrm{IC}_{50}$ value of different drugs is also given in Table I. As shown in Table $\mathrm{I}$, the $\mathrm{IC}_{50}$ value of paclitaxel, oxaliplatin, 
Table I. Effect of S100P overexpression on sensitivity of OVCAR3 cells to chemotherapeutic drugs.

\begin{tabular}{lcr}
\hline & \multicolumn{2}{c}{$\mathrm{IC}_{50}$ value $(\mu \mathrm{g} / \mathrm{ml})$} \\
Drugs & pcDNA3 & $\mathrm{S} 100 \mathrm{P}$ \\
\hline Paclitaxel & $7.31 \pm 0.35$ & $4.31 \pm 0.26^{*}(0.60)$ \\
Oxaliplatin & $14.17 \pm 0.59$ & $7.76 \pm 0.64^{*}(0.55)$ \\
5-Fluorouracil & $102.45 \pm 11.35$ & $64.15 \pm 6.49^{*}(0.62)$ \\
Etoposide & $15.76 \pm 0.49$ & $12.27 \pm 0.86^{*}(0.77)$ \\
Epirubicin & $1.04 \pm 0.14$ & $0.59 \pm 0.11^{*}(0.57)$ \\
\hline
\end{tabular}

Asterisks denote values that were significantly different from the control cells $(\mathrm{p}<0.01)$. Cell survival was determined by MTT assay. The $\mathrm{IC}_{50}$ value resulting from $50 \%$ inhibition of cell growth was calculated. Each value represents the means $\pm \mathrm{SD}$ of three independent experiments. Numbers in the parentheses represent fold-change.

5-fluorouracil, etoposide and epirubicin were significantly reduced in S100P overexpressing clones, compared to the pcDNA3 vector transfected cells $(p<0.01)$. There was a consistent increase of drug sensitivity in S100P overexpressing clones for each agent tested. The S100P gene increased sensitivity of OVCAR3 to these drugs.

S100P gene downregulation in OVCAR3 cells. Having demonstrated that S100P overexpression further sensitize OVCAR3 cells to chemotherapeutic agents, we sought to determine whether decreased S100P expression would render ovarian cancer cells more resistant to these drugs. To downregulated S100P expression, S100P-targeted siRNA was performed in this study. Silencing is more specific than overexpression for determining the role of a factor in cell biology because it avoids the problems associated with overexpression. We first determine the effect of synthetic siRNA specific to the S100P gene sequences on the inhibition S100P expression by sqRT-PCR and Western blot analysis. A S100P specific siRNA diminished the level of S100P mRNA in OVCAR3 cells by approximately $65 \%$ at $48 \mathrm{~h}$ after transfection. A siRNA consisting of a scrambled sequence with no homology to any mRNAs based on blast search was used as a negative control and had no effect on S100P mRNA levels (Fig. 3A). Furthermore, neither the S100P specific siRNA nor the scrambled siRNA induced any non-specific knockdown of $ß$-actin mRNA. Western blot analysis confirmed that the OVCAR3 cells $72 \mathrm{~h}$ after transfection with the S100P siRNA exhibited a corresponding decrease in S100P protein level with no effect on $\gamma$-tubulin protein (Fig. 3B).

Knockdown of S100P leads to increased drug resistance in OVCAR3 cells. OVCAR3 cells were transiently transfected with the synthetic S100P-targeted siRNA or negative control siRNA, followed $72 \mathrm{~h}$ later with the drug treatments for a further $48 \mathrm{~h}$, before cell viability was measured using the MTT assay. Survival rates were plotted on curves (Fig. 4). The $\mathrm{IC}_{50}$ of different drugs is also given in Table II. As shown in Table II, compared with negative control siRNA the OVCAR3 cells transfected with the synthesized S100P siRNA demonstrated increased $\mathrm{IC}_{50}$ value of paclitaxel,
A
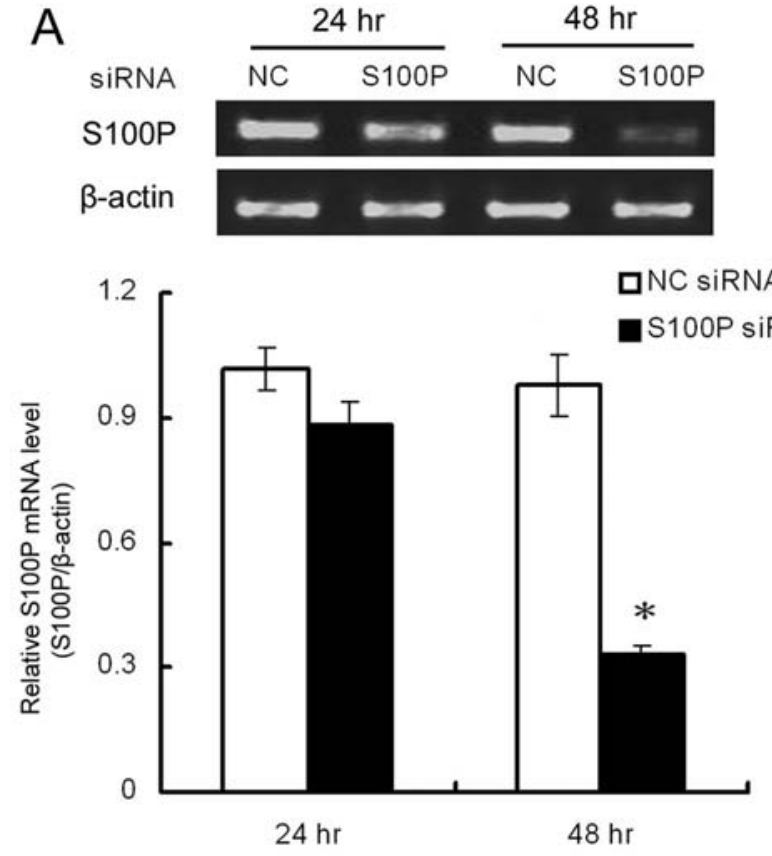

B
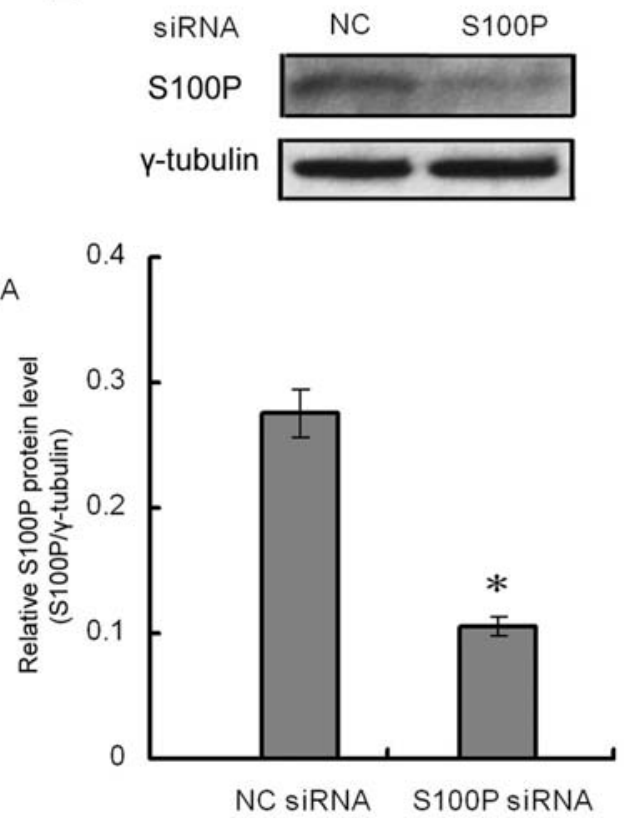

Figure 3. Effective suppression of S100P in OVCAR3 cells after transfection with small interfering RNA (siRNA)-S100P. (A) OVCAR3 cells were transfected with S100P siRNA or negative control siRNA for 24 and $48 \mathrm{~h}$. S100P levels were analyzed by semiquantitative RT-PCR. B-actin was used as internal control. The results are the representatives of at least three independent experiments. (B) OVCAR3 cells were transiently transfected with S100P-targeted siRNA or negtive control siRNA for $72 \mathrm{~h}$, and S100P levels were analyzed by Western blot analysis $\gamma$-tubulin was used as internal control. The results are the representatives of at least three independent experiments. Data values are the mean $\pm \mathrm{SD} ;{ }^{*} \mathrm{p}<0.05$ compared with negtive control siRNA. 
A

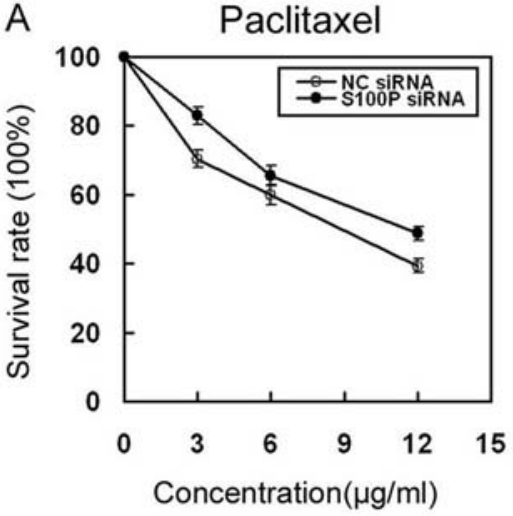

D

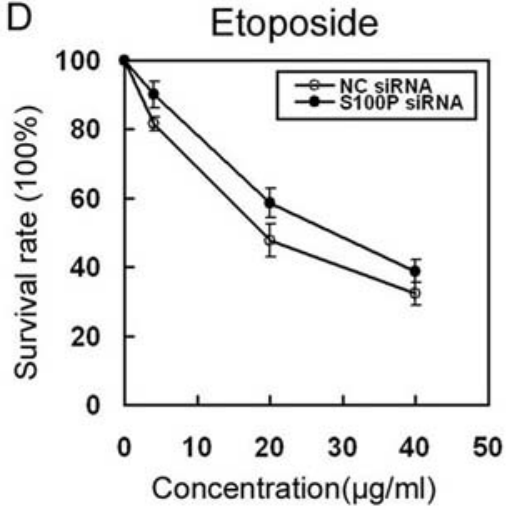

B

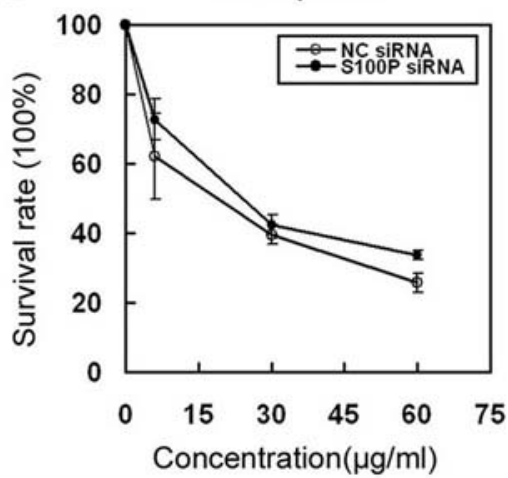

E

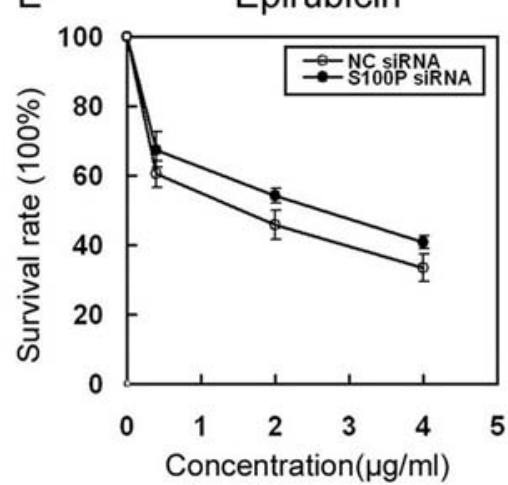

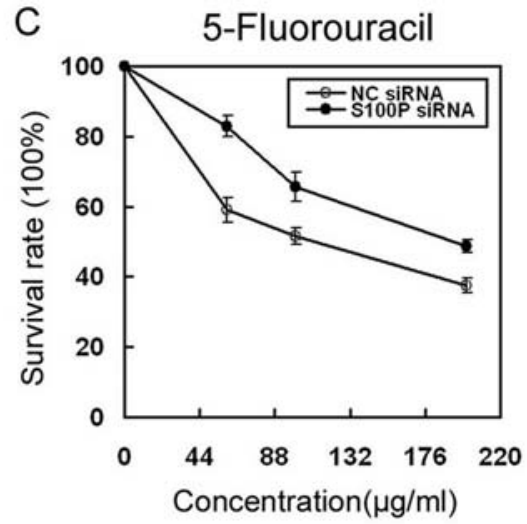

Figure 4. Enhanced resistance to chemotherapeutic drugs correlated with S100P downregulation in OVCAR3 cells. OVCAR3 cells were transiently transfected with S100P siRNA or negtive control siRNA for $72 \mathrm{~h}$ then cells were exposed for another $48 \mathrm{~h}$ at indicated concentrations of paclitaxel (A), oxaliplatin (B), 5-fluorouracil (C), etoposide (D) and epirubicin (E). Cell viability was determined by MTT assay. Knockdown of S100P leads to increased drug resistance in OVCAR3 cells. Data values are the mean \pm SD.

Table II. Effect of S100P siRNA on sensitivity of OVCAR3 cells to chemotherapeutic drugs.

\begin{tabular}{lrrr}
\hline & \multicolumn{3}{c}{$\mathrm{IC}_{50}$ value $(\mu \mathrm{g} / \mathrm{ml})$} \\
Drugs & NC siRNA & \multicolumn{1}{c}{ S100P siRNA } \\
\hline Paclitaxel & $7.93 \pm 1.20$ & $11.10 \pm 0.19^{*}$ & $(1.40)$ \\
Oxaliplatin & $11.20 \pm 3.46$ & $21.87 \pm 1.53^{*}$ & $(1.95)$ \\
5-Fluorouracil & $102.43 \pm 8.74$ & $183.46 \pm 22.38^{*}$ & $(1.79)$ \\
Etoposide & $18.66 \pm 2.52$ & $26.98 \pm 1.16^{*}$ & $(1.45)$ \\
Epirubicin & $1.12 \pm 0.36$ & $2.15 \pm 0.21^{*}$ & $(1.91)$ \\
\hline
\end{tabular}

Asterisks denote values that were significantly different from the control cells $(\mathrm{p}<0.01)$. Cell survival was determined by MTT assay. The $\mathrm{IC}_{50}$ value resulting from $50 \%$ inhibition of cell growth was calculated. Each value represents the means \pm SD of three independent experiments. Numbers in the parentheses represent fold-change.

oxaliplatin, 5-fluorouracil, etoposide and epirubicin $(\mathrm{p}<0.01)$. Knockdown of S100P leads to increased drug resistance in OVCAR3 cells. This conclusion further supported that S100P participates in the regulation of chemosensitivity to anticancer drugs in OVCAR3 cells.

\section{Discussion}

Ovarian cancer is the most common cause of death from gynecological malignancies in the United States (11). Recurrence and subsequent acquired chemoresistance are responsible for the therapeutic failure occurring in about $70 \%$ of ovarian carcinoma cases. The study of cancer drug resistance entails great challenges and opportunities for cancer chemotherapy. In a previous in vitro microarray study we demonstrated marked downregulation of S100P in oxaliplatin-resistant colorectal carcinoma cell lines (1). Moreover, we found that the level of S100P mRNA was relatively low in drug-resistance cell line. Other studies also have reported downregulation of $\mathrm{S} 100 \mathrm{P}$ in a variety of drug-resistance cells including, paclitaxelresistant prostate cancer cells (12), 5-fluorouracil-resistant colon cancer cells (13) and 5-fluorouracil-resistant gastric cancer cells (14). The above data suggest that level of S100P expression in tumor cells may be correlated with the sensitivity to chemotherapeutic drugs.

In this study we evaluated the role of S100P in ovarian cancer cells treated with chemotherapy, using OVCAR3 cell line which expresses S100P. Transfection of S100P cDNA in an expression vector into the OVCAR3 cells successfully derived S100P-overexpressing cell line. Then we selected several drugs that can induce apoptosis to cancer cells by various mechanisms, including antimicrotubule agent 
(paclitaxel), platinum compound (oxaliplatin), topoisomerase II poisons (etoposide), antimetabolites (5-fluorouracil), anthracyclines (epirubicin) to detect the role of S100P in chemosensitivity. We found that S100P overexpression in the ovarian cancer cell line reduced cell survival following exposure to all the five anticancer drugs. Correspondingly, downregulation of endogenous S100P by siRNA in the OVCAR3 cells led to resistance to these anticancer drugs. Taken together, these data provide evidence that S100P is closely associated with chemosensitivity, and its expression level causes changes of response to chemotherapeutic drugs in ovarian cancer, at least in vitro, despite the distinct damage mechanisms to cancer cells of these drugs.

Cancer cell resistance to chemotherapy can occur at many levels, including increased drug efflux and decreased drug influx; drug inactivation; alterations in drug target; processing of drug-induced damage and evasion of apoptosis (15). $\mathrm{S} 100 \mathrm{P}$ is a member of the S100 family of calcium-binding proteins, and its role is not yet completely understood. S100 proteins act as multi functional signaling factors that are involved in the regulation of diverse cellular processes. Previous studies have indicated that actin cytoskeleton, such as ezrin, an essential actin bundling protein, is a direct binding partner of S100P (16). It was observed that S100P can interact with ezrin in a $\mathrm{Ca}^{2+}$-dependent manner and influence its ability to bind actin. Increased expression of S100P led to a reduction in cortical actin, disorganization of stress fibers, and the appearance of punctate cytoplasmic accumulations (17). This normal actin cytoskeleton is required for antimicrotubule cellular action, and altering this highly regulated system can profoundly affect the sensitivity of cells to microtubule-targeted drugs (18). Paclitaxel is an antimicrotubule drug used in the treatment of ovarian, breast, and non-small cell lung cancers (19). In this study we observed that S100P affected sensitivity of cells to paclitaxel.

S100P has also been reported to be able to interact with CacyBP/SIP, a component of a novel ubiquitinylation pathway, leading to degradation of cancer related protein $B$-catenin (20). Further study showed that overexpressed CacyBP/SIP inhibits proliferation, tumorigenicity, and invasion of gastric cancer cells, via the downregulation of B-catenin (21). Chemosensitivity to these drugs of ovarian cancer may be caused by the proliferation inhibition, the result of interaction between S100P and CacyBP/SIP. However, some studies noted that $\mathrm{S} 100 \mathrm{P}$ is one of RAGE (receptor for advanced glycation endproducts) ligands, and RAGE activation by exogenously added S100P stimulates NF-кB (nuclear factor-kappaB) activation in colon cancer cells (22). NF- $\kappa \mathrm{B}$, decreased apoptotic potential of tumor cells results in their more pronounced resistance to chemotherapy (23). Expression of $\mathrm{S} 100 \mathrm{P}$ was elevated in doxorubicin-resistant colon cancer cells (6). In pancreatic cancer, S100P correlated with increased survival after 5-fluorouracil exposure (24). Therefore, mechanisms of S100P inducing chemosensitivity may be multifactorial, and the different responses to chemotherapy induced by S100P could be caused by binding different ligands in various tumor cells. Further investigation into the molecular mechanisms of S100P in drug resistance of tumor cells are needed.
In conclusion, the elucidation of the role of S100P in tumor biology remains at an early stage. Our results suggest that altering the level of S100P causes changes of sensitivity to chemotherapeutic drugs in OVCAR3 ovarian cancer cells. S100P plays an important role in drug resistance of ovarian cancer cells. Further studies of the role of S100P can provide significant insight into underlying mechanisms of drugresistance in tumor cell. Although results of in vitro assays cannot be directly extrapolated to clinical response owing to the complexity of tumor biology in humans, our findings may have therapeutic implications for use of S100P as a therapeutic target.

\section{References}

1. Tang H, Liu YJ, Liu M and Li X: Establishment and gene analysis of an oxaliplatin-resistant colon cancer cell line THC8307/L-OHP. Anticancer Drugs 18: 633-639, 2007.

2. Becker T, Gerke V, Kube E and Weber K: S100P, a novel $\mathrm{Ca}^{2+}$-binding protein from human placenta. cDNA cloning, recombinant protein expression and $\mathrm{Ca}^{2+}$ binding properties. Eur J Biochem 207: 541-547, 1992.

3. Emoto Y, Kobayashi R, Akatsuka $\mathrm{H}$ and Hidaka H: Purification and characterization of a new member of the $\mathrm{S}-100$ protein family from human placenta. Biochem Biophys Res Commun 182: 1246-1253, 1992.

4. Sato N and Hitomi J: S100P expression in human esophageal epithelial cells: Human esophageal epithelial cells sequentially produce different $\mathrm{S} 100$ proteins in the process of differentiation. Anat Rec 267: 60-69, 2002.

5. Guerreiro Da Silva ID, Hu YF, Russo IH, Ao X, Salicioni AM, Yang X and Russo J: S100P calcium-binding protein overexpression is associated with immortalization of human breast epithelial cells in vitro and early stages of breast cancer development in vivo. Int J Oncol 16: 231-240, 2000.

6. Bertram J, Palfner K, Hiddemann W and Kneba M: Elevated expression of S100P, CAPL and MAGE 3 in doxorubicinresistant cell lines: comparison of mRNA differential display reverse transcription-polymerase chain reaction and subtractive suppressive hybridization for the analysis of differential gene expression. Anticancer Drugs 9: 311-317, 1998.

7. Mousses S, Bubendorf L, Wagner U, Hostetter G, Kononen J, Cornelison R, Goldberger N, Elkahloun AG, Willi N, Koivisto P, Ferhle W, Raffeld M, Sauter G and Kallioniemi OP: Clinical validation of candidate genes associated with prostate cancer progression in the CWR22 model system using tissue microarrays. Cancer Res 62: 1256-1260, 2002.

8. Beer DG, Kardia SL, Huang CC, Giordano TJ, Levin AM, Misek DE, Lin L, Chen G, Gharib TG, Thomas DG, Lizyness ML, Kuick R, Hayasaka S, Taylor JM, Iannettoni MD, Orringer MB and Hanash S: Gene-expression profiles predict survival of patients with lung adenocarcinoma. Nat Med 8: 816-824, 2002.

9. Ohuchida K, Mizumoto K, Egami T, Yamaguchi H, Fujii K, Konomi H, Nagai E, Yamaguchi K, Tsuneyoshi M and Tanaka M: $\mathrm{S} 100 \mathrm{P}$ is an early developmental marker of pancreatic carcinogenesis. Clin Cancer Res 12: 5411-5416, 2006.

10. Eckert RL, Broome AM, Ruse M, Robinson N, Ryan D and Lee K: S100 proteins in the epidermis. J Invest Dermatol 123: 23-33, 2004.

11. Jemal A, Siegel R, Ward E, Murray T, Xu J and Thun MJ: Cancer statistics, 2007. CA Cancer J Clin 57: 43-66, 2007.

12. Takeda M, Mizokami A, Mamiya K, Li YQ, Zhang J, Keller ET and Namiki M: The establishment of two paclitaxel-resistant prostate cancer cell lines and the mechanisms of paclitaxel resistance with two cell lines. Prostate 67: 955-967, 2007.

13. Schmidt WM, Kalipciyan M, Dornstauder E, Rizovski B, Steger GG, Sedivy R, Mueller MW and Mader RM: Dissecting progressive stages of 5-fluorouracil resistance in vitro using RNA expression profiling. Int J Cancer $112: 200-212,2004$.

14. Kang HC, Kim IJ, Park JH, Shin Y, Ku JL, Jung MS, Yoo BC, Kim HK and Park JG: Identification of genes with differential expression in acquired drug-resistant gastric cancer cells using high-density oligonucleotide microarrays. Clin Cancer Res 10: 272-284, 2004. 
15. Longley DB and Johnston PG: Molecular mechanisms of drug resistance. J Pathol 205: 275-292, 2005.

16. Koltzscher M, Neumann C, Konig S and Gerke V: $\mathrm{Ca}^{2+}$-dependent binding and activation of dormant ezrin by dimeric S100P. Mol Biol Cell 14: 2372-2384, 2003.

17. Whiteman HJ, Weeks ME, Dowen SE, Barry S, Timms JF, Lemoine NR and Crnogorac-Jurcevic T: The role of S100P in the invasion of pancreatic cancer cells is mediated through cytoskeletal changes and regulation of cathepsin D. Cancer Res 67: 8633-8642, 2007.

18. Verrills NM, Liem NL, Liaw TY, Hood BD, Lock RB and Kavallaris M: Proteomic analysis reveals a novel role for the actin cytoskeleton in vincristine resistant childhood leukemia an in vivo study. Proteomics 6: 1681-1694, 2006.

19. Johnson DH, Paul DM, Hande KR, Shyr Y, Blanke C, Murphy B, Lewis M and De Vore RF III: Paclitaxel plus carboplatin in advanced non-small-cell lung cancer: a phase II trial. J Clin Oncol 14: 2054-2060, 1996.

20. Filipek A, Jastrzebska B, Nowotny M and Kuznicki J: CacyBP/ SIP, a calcyclin and Siah-1-interacting protein, binds EF-hand proteins of the S100 family. J Biol Chem 277: 28848-28852, 2002.
21. Ning X, Sun S, Hong L, Liang J, Liu L, Han S, Liu Z, Shi Y, Li Y, Gong W, Zhang S, Chen Y, Guo X, Cheng Y, Wu K and Fan D: Calcyclin-binding protein inhibits proliferation, tumorigenicity, and invasion of gastric cancer. Mol Cancer Res 5: 1254-1262, 2007.

22. Fuentes MK, Nigavekar SS, Arumugam T, Logsdon CD, Schmidt AM, Park JC and Huang EH: RAGE activation by $\mathrm{S} 100 \mathrm{P}$ in colon cancer stimulates growth, migration, and cell signaling pathways. Dis Colon Rectum 50: 1230-1240, 2007.

23. Nakanishi $\mathrm{C}$ and Toi M: Nuclear factor-kappaB inhibitors as sensitizers to anticancer drugs. Nat Rev Cancer 5: 297-309, 2005.

24. Arumugam T, Simeone DM, van Golen K and Logsdon CD: S100P promotes pancreatic cancer growth, survival, and invasion. Clin Cancer Res 11: 5356-5364, 2005. 